\title{
School Counselors' Exposure to Student Suicide, Suicide Assessment Self-Efficacy, and Workplace Anxiety: Implications for Training, Practice, and Research
}

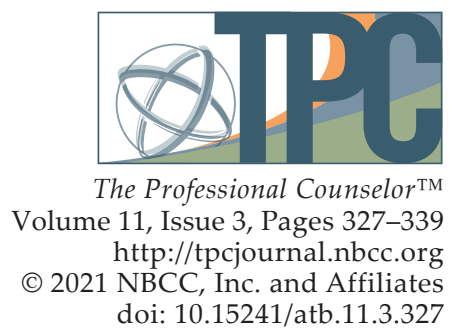

\author{
Alexander T. Becnel, Lillian Range, Theodore P. Remley, Jr.
}

In a national sample of current school counselors with membership in the American School Counselor Association $(N=226)$, we examined the prevalence of suicide training among school counselors as well as differences in suicide assessment self-efficacy and workplace anxiety between school counselors who were exposed to student suicide and those who were not. The results indicate that $38 \%$ of school counselors were not prepared for suicide prevention during graduate training. Although school counselors' exposure to suicide was not related to their workplace anxiety, those who were exposed to a student suicide attempt had higher suicide assessment self-efficacy scores than those who were not. This study demonstrates the impact of suicide exposure on school counselors and the need for additional suicide assessment training.

Keywords: school counselors, suicide, suicide assessment, self-efficacy, workplace anxiety

Suicide continues to be a growing concern for young people in the United States. Suicide is the second leading cause of death among children between the ages of 11 and 18, claiming the lives of 2,127 middle school- and high school-aged children in 2019 alone (Centers for Disease Control and Prevention [CDC], 2021). In 2019, a nationwide survey found that $18.8 \%$ of high school students reported seriously considering attempting suicide, $15.7 \%$ reported making a plan to attempt suicide, and $8.9 \%$ reported attempting suicide (Ivey-Stephenson et al., 2019). As youth suicide rates continue to rise (National Institute of Mental Health [NIMH], 2019), it is becoming increasingly important to understand how school counselors are prepared to work with suicidal youth, as well as the impact of suicidality on them.

Children and adolescents spend significant amounts of time at school, making school counselors the primary suicide and risk assessors for this population (American School Counselor Association [ASCA], 2020b). School counselors are more likely to assess youth for suicide risk than any other mental health professional (Schmidt, 2016). In 2002, a national study of ASCA members found that $30 \%$ of professional school counselors experienced a suicide-related crisis event while they were graduate student interns (Allen et al., 2002). In a more recent study, about two thirds of school counselors reported that they were conducting multiple suicide assessments each month (Gallo, 2018). Stickl Haugen et al. (2021) found that $79.8 \%$ of school counselors worked with a student who had previously attempted suicide and 36.7\% experienced a student's death by suicide. As school counselors become more frequently exposed to student suicide, it is important to understand their preparation for this role and the impact of these events on the school counselors themselves.

\section{School Counselor Suicide and Crisis Training}

Although school counselors are often exposed to student suicide, many school counselors lack appropriate crisis intervention and suicide assessment training (Allen et al., 2002; Springer et al., 2020;

Alexander T. Becnel, PhD, NCC, LPC, is a doctoral candidate at the University of Holy Cross. Lillian Range, PhD, is a professor at the University of Holy Cross. Theodore P. Remley, Jr., JD, PhD, NCC, is a professor at the University of Holy Cross. Correspondence may be addressed to Alexander T. Becnel, 4123 Woodland Drive, New Orleans, LA 70131, abecnel2@uhcno.edu. 
Wachter Morris \& Barrio Minton, 2012) and lack confidence in their ability to assess students for suicide risk (Gallo, 2018; Schmidt, 2016). About 20 years ago, one third of school counselors entered the field without any formal crisis intervention coursework and nearly $60 \%$ did not feel adequately prepared to handle a school crisis event (Allen et al., 2002). Ten years later, school counselors did not fare any better, with less than a quarter of school counselors reporting that they completed a course in crisis intervention and nearly two thirds reporting that a crisis intervention course was not even offered during their master's program (Wachter Morris \& Barrio Minton, 2012). Not surprisingly, therefore, school counselors feel unprepared. In a national survey, $44 \%$ of school counselors reported being unprepared for a student suicide attempt, and $57 \%$ reported being unprepared for a student's death by suicide (Solomonson \& Killam, 2013). In another national survey, Gallo (2018) found that only 50\% of school counselors thought that their training adequately prepared them to assess suicidal students, and only $59 \%$ felt prepared to recognize a student who was at risk. These results are especially troubling considering that the Council for Accreditation of Counseling and Related Educational Programs (CACREP) requires school counselor education programs to provide both suicide prevention and suicide assessment training (CACREP, 2015).

\section{Exposure to Suicide and Self-Efficacy}

Mental health professionals often question their professional judgment following an exposure to suicide (Sherba et al., 2019; Thomyangkoon \& Leenars, 2008). Consequently, it is imperative to explore school counselor self-efficacy in the aftermath of a student suicide. Self-efficacy is the degree to which individuals believe that that they can achieve self-determined goals, and individuals are more likely to be successful in achieving those goals simply by belief in their success (Bandura, 1986). Counselor self-efficacy is defined as counselors' judgment of their ability to provide counseling to their clients (Larson et al., 1992). As counselors spend more years in practice, their self-efficacy increases (Goreczny et al., 2015; Kozina et al., 2010; Lent et al., 2003). Further, counselor education faculty have significantly higher levels of suicide assessment self-efficacy than their students (Douglas \& Wachter Morris, 2015). The relationship between counselor self-efficacy and work experience is well documented, so it is imperative to control for years of counseling experience as a potential covariate when studying other factors that can affect counselor self-efficacy.

Although the literature regarding school counselors' exposure to suicide is sparse, more studies have focused on the experiences of related professions, such as clinical counselors, social workers, psychiatrists, and psychologists. In a national survey, $23 \%$ of clinical counselors experienced a client's death by suicide at some point in their career (McAdams \& Foster, 2002). In the aftermath of their clients' deaths by suicide, those counselors reported a loss of self-esteem and an increase of intrusive thoughts. They increased referrals for hospitalization for clients at risk, gave increased attention to signs for suicide, and increased their awareness of legal liabilities in their practices. In a study of community-based mental health professionals who experienced a client death by suicide, one third considered changing careers and about $15 \%$ considered early retirement in the aftermath of the suicide (Sherba et al., 2019). Psychologists who felt responsible for the death were more likely to experience a sense of professional incompetence (Finlayson \& Graetz Simmonds, 2018). Among psychiatrists, those who experienced a patient's suicidal death were more likely in the future to suggest hospitalization for patients who showed risk signs for suicide (Greenberg \& Shefler, 2014). Additionally, $20 \%$ of the psychiatrists in Thomyangkoon and Leenars's (2008) study considered changing professions after experiencing a patient death by suicide. Given the similarities in these professions, it is reasonable to suggest that school counselors may feel more anxious about their jobs following a suicide exposure.

To date, there are only three published studies that explore suicide exposures among school counselors (Christianson \& Everall, 2008; Gallo et al., 2021; Stickl Haugen et al., 2021). In a qualitative 
study, high school counselors felt a lack of personal support from their fellow staff members and noted the importance of self-care in the aftermath of a student death by suicide. Additionally, those who lost students to suicide thought that a lack of practice standards made it difficult to navigate these difficult situations (Christianson \& Everall, 2008). In another qualitative study, elementary school counselors who worked with suicidal students recognized their important work in preventing suicide but also reported a lack of suicide prevention training opportunities tailored toward working with young children (Gallo et al., 2021). In a quantitative study, most school counselors thought that a student's death by suicide left both personal and professional impacts on their lives. These school counselors most often reported low mood, a sense of guilt or responsibility, and preoccupation with the incident as personal impacts. They also identified heightened awareness of suicide risk, more professional caution around suicide, and seeking additional training as professional impacts. The researchers suggested that future studies should determine if the number of student deaths by suicide influences the impact of the suicide exposure (Stickl Haugen et al., 2021). However, this study did not examine anxiety, an important personal impact, nor did it examine self-efficacy in dealing with suicide attempts, a more likely occurrence than suicide deaths.

\section{Research Questions}

The following research questions guided this study:

- What is the prevalence of graduate and postgraduate training in suicide prevention, crisis intervention, and suicide postvention among current school counselors?

- Are there differences in suicide assessment self-efficacy between school counselors exposed and not exposed to student deaths by suicide and suicide attempts, controlling for years of school counseling experience as a covariate?

- Does the number of suicide exposures relate to school counselors' level of suicide assessment self-efficacy when controlling for years of school counseling experience as a covariate?

- Are there differences in workplace anxiety between school counselors exposed and not exposed to student deaths by suicide and suicide attempts, controlling for years of school counseling experience as a covariate?

\section{Method}

\section{Procedure}

We obtained approval from our university's Human Subjects Protection Review Committee prior to conducting this study. Using a random number generator, we randomly selected 5,000 members from the ASCA member directory to receive a link to the survey. When potential participants clicked the link, they viewed and agreed to an informed consent statement before they were permitted to view the survey. This statement also informed participants that they could stop participation or withdraw their participation at any time. Upon agreement to the informed consent statement, participants were directed to the survey. This online survey was administered via Qualtrics, which allowed them to respond anonymously.

\section{Participants}

From the 5,000 potential participants, 422 began the survey. From these participants, 101 opened the survey and did not answer any questions, 5 did not agree to the informed consent statement, 29 reported that they were not current school counselors, and 60 did not complete the survey. Thus, 226 of 
the 5,000 ASCA members completed the survey (4.52\%). An a priori power analysis (Cohen, 1992) with a power of .8, a medium effect size, and $\alpha=.05$ determined that the required sample size for our most robust test was 175 .

Participants were 226 current school counselors (201 women, 88.9\%; 25 men, 11.1\%). The racial categories included 192 White (85\%), nine Black or African American (4\%), eight "other" races (3.5\%), six Asian (2.7\%), five biracial or multiracial (2.2\%), three American Indian or Alaska Native $(1.3 \%)$, and three not reporting race (1.3\%). The ethnicity categories included 210 participants $(92.9 \%)$ who were not of Hispanic or Latino or Spanish origin and 16 (7.1\%) who were of Hispanic or Latino or Spanish origin. The mean age was 39 years $(S D=10.68)$, and the mean years of experience working as a school counselor was $7(S D=6.98)$. With regard to school setting, 52 school counselors worked in an elementary or primary school (23\%), 58 worked in a middle or junior high school (25.7\%), 81 worked in a high school (35.8\%), 19 worked in a K-12 school (8.4\%), and 16 worked in another type of school not listed (7.1\%). Although ASCA does not provide demographic information about their members, this sample is similar in its demographic makeup to the sample in Gilbride et al.'s (2016) study, which sought to describe the demographic identity of ASCA's membership.

\section{Instrumentation}

The survey packet consisted of three instruments: the demographic questionnaire, the Counselor Suicide Assessment Efficacy Survey (CSAES; Douglas \& Wachter Morris, 2015), and the Workplace Anxiety Scale (WAS; McCarthy et al., 2016).

\section{Demographic Questionnaire}

Using a demographic questionnaire, we asked participants to identify the following information: sex, race, ethnicity, age, years of school counseling experience, and school type (e.g., high school, middle school). Additionally, we asked participants to identify the types of suicide exposures that they have encountered in their school counseling careers. If they reported exposure to either deaths by suicide or suicide attempts, the survey followed up with additional questions about the number of exposures, the amount of time since the first suicide exposure, and the amount of time since the most recent suicide exposure. We asked participants if their schools had crisis plans or crisis teams. We also asked participants if they had training in suicide prevention, crisis intervention, and suicide postvention during graduate school and the number of postgraduate training hours in each of these areas.

\section{CSAES}

The CSAES evaluates counselors' confidence in their ability to assess clients for suicide risk and intervene with a client at risk of suicide. It includes 25 items in four subscales: General Suicide Assessment, Assessment of Personal Characteristics, Assessment of Suicide History, and Suicide Intervention. Each item is rated on a 5-point Likert scale from 1 (not confident) to 5 (highly confident). High scores indicate high self-efficacy. Among school counselors in the original study, each subscale had good internal consistency ( $\alpha=.88-.81$ ) and acceptable goodness of fit. As suggested by Douglas and Wachter Morris (2015), we scored each subscale separately and averaged each score. This process created four comparable subscale scores.

\section{WAS}

The WAS measures participants' job-related anxiety. This scale asks participants to rate eight items such as "I worry that my work performance will be lower than that of others at work" on a 5-point scale from 1 (strongly disagree) to 5 (strongly agree). High scores on the WAS indicate higher levels of job-related anxiety. The WAS demonstrated good internal consistency $(\alpha=.94)$ and acceptable goodness of fit (McCarthy et al., 2016). 


\section{Data Analysis}

To address our first research question, we used descriptive statistics to examine the prevalence of training among the participants. We used analysis of covariance (ANCOVA) to detect differences in both suicide assessment self-efficacy (CSAES scores) and workplace anxiety (WAS scores) while controlling for years of school counseling experience between school counselors who were exposed to student suicide and those who were not. We considered exposure to deaths by suicide and exposure to suicide attempts as different types of exposure. Therefore, we performed a total of four ANCOVAs: (a) differences in CSAES scores between school counselors exposed to deaths by suicide and those not exposed, (b) differences in CSAES scores between school counselors exposed to suicide attempts and those not exposed, (c) differences in WAS scores between school counselors exposed to deaths by suicide and those not exposed, and (d) differences in WAS scores between school counselors exposed to suicide attempts and those not exposed. We also used analysis of variance (ANOVA) to determine the difference in years of school counseling experience between those exposed to suicide and those not exposed. To determine the relationship between the number of suicide exposures and counselor suicide assessment self-efficacy, we also completed two partial correlations between the number of exposures to student death by suicide and CSAES scores, and the number of exposures to student suicide attempts and CSAES scores.

\section{Results}

A total of 64 school counselors reported that they experienced a student death by suicide during their school counseling experience $(28.3 \%)$, with a mean of 2.11 deaths $(S D=2.21)$. On average, their first suicide death was 6.72 years ago $(S D=5.87)$, and the most recent suicide death was 3.84 years ago $(S D=3.88)$. A total of 124 participants experienced a student suicide attempt during their school counseling experience $(54.9 \%)$, with a mean of 5.36 attempts $(S D=10.54)$. On average, the first suicide attempt was 5.91 years ago $(S D=6.07)$, and the most recent attempt was 1.82 years ago $(S D=2.10)$. Of all 226 school counselors, 195 worked in schools that have crisis plans $(86.3 \%)$, and 170 worked in schools that have crisis teams $(75.2 \%)$.

\section{Suicide Training}

Regarding suicide prevention training during their graduate program, 140 (62\%) received some training, but $86(38 \%)$ received no training. Regarding crisis intervention training during their graduate program, 142 (63\%) received some, but 84 (37\%) received none. Regarding suicide postvention, only 87 $(38.5 \%)$ received some, but 139 (61.5\%) received none. The number of postgraduate training hours varied widely for each preparation type. For suicide prevention, training hours averaged $12.20(S D=28.61)$; for crisis intervention, training hours averaged $9.04(S D=15.51)$; and for suicide postvention, training hours averaged $6.45(S D=18.14)$. We removed one participant's postgraduate training data that was more than 3 standard deviations higher than the mean. In order to better illustrate the distribution of postgraduate training hours, we grouped the number of training hours into four categories: 0 hours, 1-10 hours, 11-50 hours, and more than 50 hours of postgraduate training. Nearly a quarter of the participants $(24.3 \%)$ received no postgraduate training in suicide prevention, about a third of the participants $(30.5 \%)$ received no postgraduate training in crisis intervention, and half $(50.4 \%)$ received no postgraduate training in suicide postvention.

To further demonstrate the disparity of suicide training, cross-tabulation was performed between graduate training and the number of postgraduate training hours. We reported this data in Table 1. Most surprisingly, 25 school counselors (11.1\%) received no graduate training in suicide prevention, nor any postgraduate hours of training in suicide prevention; another 45 (19.9\%) received no graduate training and only 10 or fewer hours of postgraduate training in suicide prevention, making 
nearly 1 in 3 school counselors unprepared to provide suicide prevention services. Crisis intervention fared similarly with 26 school counselors $(11.5 \%)$ reporting no graduate training and no postgraduate training hours and 41 school counselors (18.1\%) reporting no graduate training and 10 or fewer postgraduate training hours. Again, nearly 1 in 3 school counselors were not adequately prepared to provide this important service. Crisis postvention fared the worst, with 80 school counselors $(35.4 \%)$ reporting that they received no graduate training and no postgraduate training hours, and 46 school counselors (20.4\%) reporting no graduate training and fewer than 10 hours of postgraduate training. More than half of the school counselors surveyed are unprepared to face the aftermath of a suicide.

Table 1

Graduate Training and Postgraduate Training Hours

\begin{tabular}{|c|c|c|c|c|}
\hline \multirow[t]{2}{*}{$\begin{array}{c}\text { Number of postgraduate } \\
\text { training hours }\end{array}$} & \multicolumn{2}{|c|}{ Received graduate training } & \multicolumn{2}{|c|}{ Did not receive graduate training } \\
\hline & Frequency & Percentage & Frequency & Percentage \\
\hline \multicolumn{5}{|l|}{ Suicide Prevention } \\
\hline 0 hours & 30 & 13.3 & 25 & 11.1 \\
\hline 1-10 hours & 73 & 32.3 & 45 & 19.9 \\
\hline $11-50$ hours & 29 & 12.8 & 15 & 6.6 \\
\hline 50 or more hours & 8 & 3.6 & 1 & 0.4 \\
\hline Total & 140 & 62.0 & 86 & 38.0 \\
\hline \multicolumn{5}{|l|}{ Crisis Intervention } \\
\hline 0 hours & 43 & 19.0 & 26 & 11.5 \\
\hline $1-10$ hours & 69 & 30.5 & 41 & 18.1 \\
\hline $11-50$ hours & 26 & 11.5 & 16 & 7.0 \\
\hline 50 or more hours & 4 & 1.8 & 1 & 0.4 \\
\hline Total & 142 & 63.0 & 84 & 37.0 \\
\hline \multicolumn{5}{|l|}{ Suicide Postvention } \\
\hline 0 hours & 34 & 15.0 & 80 & 35.4 \\
\hline 1-10 hours & 37 & 16.4 & 46 & 20.4 \\
\hline $11-50$ hours & 12 & 5.3 & 11 & 4.8 \\
\hline 50 or more hours & 4 & 1.8 & 2 & 0.9 \\
\hline Total & 87 & 38.5 & 139 & 61.5 \\
\hline
\end{tabular}

\section{Suicide Exposure and Suicide Assessment Self-Efficacy}

An ANOVA indicated that school counselors exposed to a student death by suicide had significantly more years of school counseling experience $(M=11.9, S D=7.87)$ than school counselors not exposed to a student death by suicide $(M=5.1, S D=5.56): F(1,224)=21.512, p<.001$. Controlling for years of school counseling experience as a covariate, an ANCOVA indicated that there was no significant difference 
between these two groups in General Suicide Assessment, $F(1,223)=.316, p=.574$; Assessment of Personal Characteristics, $F(1,223)=.156, p=.694$; Suicide Intervention, $F(1,223)=.028, p=.867$; or Assessment of Suicide History, $F(1,223)=1.095, p=.133$.

Similarly, results of an ANOVA indicated that school counselors exposed to student suicide attempts had significantly more years of school counseling experience $(M=8.8, S D=7.31)$ than counselors not exposed $(M=4.9, S D=5.94): F(1,224)=8.055, p=.005$. Controlling for years of school counseling experience, an ANCOVA indicated significant differences between the two groups in General Suicide Assessment, $F(1,223)=6.014, p=.015$; Assessment of Personal Characteristics, $F(1,223)=7.140, p=.008$; and Suicide Intervention, $F(1,223)=6.671, p=.010$; but not Assessment of Suicide History, $F(1,223)=.763$, $p=.383$. Overall, effect sizes were small.

\section{Number of Exposures and Self-Efficacy}

A partial correlation between the number of suicide exposures and CSAES scores while controlling for years of school counseling experience was not statistically significant. There was no significant relationship between the number of death by suicide exposures and General Suicide Assessment, $r(61)=.137, p=.285$; Assessment of Suicide History, $r(61)=.207, p=.104$; Assessment of Personal Characteristics, $r(61)=.170, p=.184$; or Suicide Intervention, $r(61)=.077, p=.551$. Likewise, there was also no significant relationships between the number of suicide attempt exposures and General Suicide Assessment, $r(121)=-.028, p=.762$; Assessment of Suicide History, $r(121)=.087, p=.336$; Assessment of Personal Characteristics, $r(121)=.131, p=.150$; or Suicide Intervention, $r(121)=.076, p=.401$. We reported data regarding the frequency of suicide exposure in Table 2.

\section{Suicide Exposure and Workplace Anxiety}

In WAS scores, an ANCOVA revealed that there were no significant differences between school counselors exposed and not exposed to a student death by suicide when controlling for years of school counseling experience: $F(1,223)=.412, p=.522$. Likewise, an ANCOVA revealed that there was no significant difference in WAS scores between school counselors exposed and not exposed to student suicide attempts when controlling for years of school counseling experience: $F(1,223)=.238, p=.626$. To further illustrate the relationship between years of school counseling experience and workplace anxiety, a correlation coefficient indicated that these measures were significantly related, $r(224)=-.260, p<.001$.

\section{Discussion}

Among these school counselors, more than a quarter experienced a student's death by suicide and over half experienced a student's suicide attempt. These results are consistent with previous studies indicating that many school counselors will eventually be exposed to a student suicide during their careers (Allen et al., 2002; Gallo, 2018; Schmidt, 2016; Stickl Haugen et al., 2021). Given how common suicide experiences are, school counselors need to be trained to manage suicide-related crises.

\section{Training}

A surprising result in our study was the overall lack of suicide and crisis training reported. As seen in Table 1, nearly 2 in 5 school counselors (38\%) reported that they received no suicide prevention training during their graduate education. Additionally, a quarter of the school counselors in this study reported that they received no postgraduate training in suicide prevention, and half reported between 1 and 10 hours. Thus, a sizeable portion of these school counselors were not adequately trained to incorporate suicide prevention programs into their school counseling practice. This finding echoes Gallo (2018), who reported that only $60 \%$ of school counselors felt prepared to identify students at risk for suicide. 
These rates are poor considering that CACREP requires suicide assessment and suicide prevention training as a standard of all counselor education programs (CACREP, 2015). Further, ASCA states that school counselors are responsible for identifying students at risk for suicide and ensuring that suicide prevention programs are in place in schools (ASCA, 2020a). The lack of training reported in this study is particularly troubling given that all of the participants in this study were members of ASCA.

\section{Table 2}

Frequency of Student Suicide Exposure

\begin{tabular}{|c|c|c|}
\hline Variable & Frequency & Percentage \\
\hline \multicolumn{3}{|c|}{ Number of student deaths by suicide $(n=64)$} \\
\hline 1 & 37 & 57.8 \\
\hline 2 & 15 & 23.4 \\
\hline $3-5$ & 8 & 12.5 \\
\hline$>5$ & 4 & 6.3 \\
\hline \multicolumn{3}{|c|}{ Years since first death by suicide $(n=64)$} \\
\hline Within 1 year & 12 & 18.8 \\
\hline 1 and 5 years & 25 & 39.0 \\
\hline 6 and 10 years & 12 & 18.8 \\
\hline More than 10 years & 15 & 23.4 \\
\hline \multicolumn{3}{|c|}{ Years since most recent death by suicide $(n=64)$} \\
\hline Within 1 year & 23 & 35.9 \\
\hline Between 1 and 5 years & 26 & 40.6 \\
\hline Between 6 and 10 years & 11 & 17.2 \\
\hline More than 10 years & 4 & 6.3 \\
\hline \multicolumn{3}{|c|}{ Number of student suicide attempts $(n=124)$} \\
\hline 1 & 29 & 23.4 \\
\hline 2 & 29 & 23.4 \\
\hline $3-5$ & 44 & 35.5 \\
\hline$>5$ & 22 & 17.7 \\
\hline \multicolumn{3}{|c|}{ Years since first student attempt $(n=124)$} \\
\hline Within 1 year & 30 & 24.2 \\
\hline Between 1 and 5 years & 51 & 41.1 \\
\hline Between 6 and 10 years & 21 & 17.0 \\
\hline More than 10 years & 22 & 17.7 \\
\hline \multicolumn{3}{|c|}{ Years since most recent attempt $(n=124)$} \\
\hline Within 1 year & 84 & 67.7 \\
\hline Between 1 and 5 years & 33 & 26.6 \\
\hline Between 6 and 10 years & 6 & 4.8 \\
\hline More than 10 years & 1 & 0.8 \\
\hline
\end{tabular}


Crisis intervention training among school counselors also was poor. Comparable to the finding on suicide prevention training, a third of these school counselors reported no graduate training in crisis intervention. Further, more than a third reported that they did not receive postgraduate training hours in crisis intervention, and nearly half received between 1 and 10 hours of postgraduate training. A significant portion of these school counselors were not adequately prepared to respond to crises in their schools. These findings are slightly worse than the findings from 20 years ago when one third of a sample of school counselors reported that they entered the field with no formal crisis intervention coursework (Allen et al., 2002). However, these findings are much better than Wachter Morris and Barrio Minton's (2012) study in which only 20\% of school counselors completed a course in crisis intervention during their master's degree program. Although preparation has increased, crisis preparation for school counseling students must continue to improve given that school counselors regularly experience crises (Wachter, 2006) and school counseling students often experience crises while still in graduate school completing their practicum or internship (Wachter Morris \& Barrio Minton, 2012). The number of school counselors who experienced a student suicide event in the current study also supports the notion that school counselors regularly experience crises.

Most of these school counselors (61.5\%) were not trained in their graduate programs for suicide postvention. Half of the surveyed school counselors reported that they received no postgraduate training hours in suicide postvention, with an additional 38\% reported having received between 1 and 10 hours of postgraduate training. These results demonstrate that the vast majority of school counselors are not prepared to respond to a student's suicidal death. This finding is distressing because school counselors play a vital role in the aftermath of a student suicide (Maples et al., 2005; Substance Abuse and Mental Health Services Administration [SAMHSA], 2016).

\section{Suicide Assessment Self-Efficacy}

Among these counselors, exposure to suicide alone did not make a difference with their suicide assessment self-efficacy or workplace anxiety. Years of school counseling experience appears to have a much more important role in suicide assessment self-efficacy and reduced anxiety than experiencing a student's death by suicide. This result supports previous studies that found that years of experience has a positive relationship with self-efficacy (Douglas \& Wachter Morris, 2015; Kozina et al., 2010; Lent et al., 2003). It also parallels the previous finding that the impact of a client's suicidal death on a mental health practitioner decreases as the practitioner gains years of experience (McAdams \& Foster, 2002). This result is different from Stickl Haugen et al.'s (2021) finding that school counselors who were exposed to a student death had higher levels of suicide assessment self-efficacy than those not exposed. However, Stickl Haugen et al. did not control for years of school counseling experience.

In contrast, exposure to suicide attempts did make a difference in suicide assessment self-efficacy. Even after controlling for years of experience, counselors with suicide attempt experience reported more efficacy in three of four subscales: General Suicide Assessment, Assessment of Personal Characteristics, and Suicide Intervention. One explanation for this outcome is that a student suicide attempt experience might motivate school counselors to learn about suicide and the risk factors associated. This explanation echoes Wagner et al.'s (2020) finding that counselors found additional training in the aftermath of a suicide very helpful. Many of the school counselors in the current study received no formal training, so it is possible that these experiences helped them fill in knowledge gaps, which in turn increased their self-efficacy. Training increases self-efficacy (Al-Darmaki, 2004; Mirick et al., 2016; Wachter Morris \& Barrio Minton, 2012), so it is also possible that this experience worked as an in vivo training for these school counselors, increasing their self-efficacy. 


\section{Workplace Anxiety}

Although mental health clinicians often experience symptoms of anxiety in the wake of a student suicide (McAdams \& Foster, 2002; Sherba et al., 2019), present results suggest that a student's death or suicide attempt does not have an impact on school counselors' workplace anxiety. One explanation for this finding is the relationship between self-efficacy and anxiety. Overall, these school counselors had high self-efficacy scores in each of the four subscales. Previous research indicated that as self-efficacy increases, anxiety decreases (Bodenhorn \& Skaggs, 2005; Gorecnzy et al., 2015; Larson et al., 1992). The death by suicide experience might not have impacted the counselors' anxiety in this study because of their overall high self-efficacy. Another explanation is that the school counselors in this study had on average several years of experience $(M=7.05)$. Workplace anxiety levels decrease as school counselors spend more time on the job.

\section{Implications}

These results have several implications for school counselors and school counselor educators. First, school counselor educators and school counseling graduate programs should be aware of both the overall disparity of graduate-level suicide and crisis training as well as the benefits that training can provide to future school counselors. Regarding suicide prevention, crisis intervention, and suicide postvention, there are far too many untrained school counselors among the current body of school counselors. School counseling students are a vulnerable group when it comes to suicide assessment self-efficacy (Douglas \& Wachter Morris, 2015), so it is imperative to support their professional development. School counseling graduate programs must increase their efforts to adequately train and prepare school counselors for suicide prevention, assessment, and intervention.

Second, school counselors should prepare to face the probability of having to deal with student suicide attempts and student deaths by suicide. If school counselors do not receive this training during their graduate programs, then they must seek continuing education opportunities that address suicide prevention, crisis intervention, and suicide postvention. Suicide and crisis training increases counselor self-efficacy (Mirick et al., 2016; Wachter Morris \& Barrio Minton, 2012), making appropriate preparation vital. Additionally, school counselors could consider clinical supervision as a supplemental layer of support. School counselors receive supervision at much lower rates than their clinical counterparts (Perera-Diltz \& Mason, 2012) even though many school counselors desire more supervision (Cook et al., 2012). Given that school counseling-focused supervision can increase self-efficacy (Tang, 2019) and school counselors feel a lack of personal support in the aftermath of a suicide (Christianson \& Everall, 2008), school counselors must seek clinical supervision.

Finally, school counselor educators should consider training efforts that focus specifically on student suicide attempts. In the current study, school counselors exposed to a suicide attempt were more efficacious than school counselors not exposed to a student suicide attempt. Modeling these experiences through the use of specific role plays could help school counseling students feel more confident about their suicide assessment capabilities. Although CACREP does not require counselor education programs to provide suicide postvention training (CACREP, 2015), perhaps standards should adapt to include this important training area. Regardless, programs should also emphasize this training to best prepare school counselors.

\section{Limitations and Suggestions for Future Research}

Some factors limited this study. Although we had a national sample, we surveyed only current members of ASCA. It is possible that school counselors who are not members of ASCA might have responded differently. The study also had a low response rate (4.64\%). Those school counselors who 
responded may be uniquely interested in this area, so the results may not reflect all school counselors. This study also did not limit the types of school counselors who could participate. It is possible that school counselors who work with younger children, such as elementary and primary school counselors, have less familiarity with suicide assessment and intervention than those school counselors who work with older children. The inclusion of these counselors could have affected the results of this study. Finally, this study did not ask participants if they graduated from a CACREP-accredited program. Because suicide prevention and assessment training are required components of CACREP-accredited programs, it is possible that school counselors who graduated from these programs may have different levels of training and self-efficacy than those trained in unaccredited programs.

For future studies, researchers should consider limiting their samples to specific levels of schooling such as elementary, middle, or high school. This change would help illustrate the nuanced differences among school counselors in different academic environments as well as increase focus on the school counselors who most often work with suicidal students. Future studies should also consider surveying a sample that includes all school counselors, not just ASCA members. Researchers should also differentiate between school counselors who graduated from CACREP-accredited programs and those who did not. Collecting this data would allow researchers to detect if there are any differences in suicide assessment training and self-efficacy between these two groups. Finally, future researchers should consider designing a study that seeks to identify the factors that most impact suicide assessment self-efficacy. Although this study showed that a suicide attempt experience could impact suicide assessment self-efficacy, other factors, such as self-confidence, could have a larger influence.

Suicide continues to be understudied in school counseling. Even though this study demonstrates the high likelihood that a school counselor will experience a student suicide, school counselors continue to report a lack of preparation in suicide prevention, crisis intervention, and suicide postvention. Although school counselors who experienced a student suicide attempt appeared to gain self-efficacy from their experiences, additional training in counseling suicidal students might help school counselors feel prepared before they face such serious situations. If additional training can help school counselors save students from suicide, then efforts must be made to adequately prepare them.

\section{Conflict of Interest and Funding Disclosure}

The authors reported no conflict of interest or funding contributions for the development of this manuscript.

\section{References}

Al-Darmaki, F. R. (2004). Counselor training, anxiety, and counseling self-efficacy: Implications for training psychology students from the United Arab Emirates University. Social Behavior and Personality: An International Journal, 32(5), 429-439. https://doi.org/10.2224/sbp.2004.32.5.429

Allen, M., Burt, K., Bryan, E., Carter, D., Orsi, R., \& Durkan, L. (2002). School counselors' preparation for and participation in crisis intervention. Professional School Counseling, 6(2), 96-102.

American School Counselor Association. (2020a). The school counselor and suicide risk assessment. https://school counselor.org/Standards-Positions/Position-Statements/ASCA-Position-Statements/The-School-Coun selor-and-Suicide-Risk-Assessment 
American School Counselor Association. (2020b). The school counselor and student mental health. https://schoolc ounselor.org/Standards-Positions/Position-Statements/ASCA-Position-Statements/The-School-Couns elor-and-Student-Mental-Health

Bandura, A. (Ed.). (1986). Social foundations of thought and action: A social cognitive theory. Prentice Hall.

Bodenhorn, N., \& Skaggs, G. (2005). Development of the School Counselor Self-Efficacy Scale. Measurement and Evaluation in Counseling and Development, 38(1), 14-28. https://doi.org/10.1080/07481756.2005.11909766

Centers for Disease Control and Prevention. (2021). Injury center: Violence prevention: Suicide prevention. https://webappa.cdc.gov/sasweb/ncipc/leadcause.html

Christianson, C. L., \& Everall, R. D. (2008). Constructing bridges of support: School counsellors' experiences of student suicide. Canadian Journal of Counselling, 42(3), 209-221.

Cohen, J. (1992). A power primer. Psychological Bulletin, 112(1), 155-159. https://doi.org/10.1037//0033-2909.112.1.155

Cook, K., Trepal, H., \& Somody, C. (2012). Supervision of school counselors: The SAAFT model. Journal of School Counseling, 10(21). https://files.eric.ed.gov/fulltext/EJ981202.pdf

Council for Accreditation of Counseling and Related Educational Programs. (2015). 2016 CACREP standards. http://www.cacrep.org/wp-content/uploads/2017/08/2016-Standards-with-citations.pdf

Douglas, K. A., \& Wachter Morris, C. A. (2015). Assessing counselors' self-efficacy in suicide assessment and intervention. Counseling Outcome Research and Evaluation, 6(1), 58-69. https://doi.org/10.1177/2150137814567471

Finlayson, M., \& Graetz Simmonds, J. (2018). Impact of client suicide on psychologists in Australia. Australian Psychologist, 53(1), 23-32. https://doi.org/10.1111/ap.12240

Gallo, L. L. (2018). The relationship between high school counselors' self-efficacy and conducting suicide risk assessments. Journal of Child and Adolescent Counseling, 4(3), 209-225. https://doi.org/10.1080/23727810.2017.1422646

Gallo, L. L., Rausch, M. A., Beck, M. J., \& Porchia, S. (2021). Elementary school counselors' experiences with suicidal students, Journal of Child and Adolescent Counseling, 7(1), 26-41. https://doi.org/10.1080/23727810.2020.1835419

Gilbride, D. D., Goodrich, K. M., \& Luke, M. (2016). The professional peer membership of school counselors and the resources used within their decision-making. The Journal of Counselor Preparation and Supervision, 8(2). https://repository.wcsu.edu/jcps/vol8/iss2/4

Goreczny, A. J., Hamilton, D., Lubinski, L., \& Pasquinelli, M. (2015). Exploration of counselor self-efficacy across academic training. The Clinical Supervisor, 34(1), 78-97. https://doi.org/10.1080/07325223.2015.1012916

Greenberg, D., \& Shefler, G. (2014). Patient suicide. Israel Journal of Psychiatry \& Related Sciences, 51(3), $193-198$. Ivey-Stephenson, A. Z., Demissie, Z., Crosby, A. E., Stone, D. M., Gaylor, E., Wilkins, N., Lowry, R., \& Brown, M. (2019). Suicidal ideation and behaviors among high school students - Youth Risk Behavior Survey, United States, 2019. Morbidity and Mortality Weekly Report, Supplement 69(1), 47-55. https://doi.org/10.15585/mmwr.su6901a6

Kozina, K., Grabovari, N., De Stefano, J., \& Drapeau, M. (2010). Measuring changes in counselor self-efficacy: Further validation and implications for training and supervision. The Clinical Supervisor, 29(2), 117-127. https://doi.org/10.1080/07325223.2010.517483

Larson, L. M., Suzuki, L. A., Gillespie, K. N., Potenza, M. T., Bechtel, M. A., \& Toulouse, A. L. (1992). Development and validation of the Counseling Self-Estimate Inventory. Journal of Counseling Psychology, 39(1), 105-120. https://doi.org/10.1037/0022-0167.39.1.105

Lent, R. W., Hill, C. E., \& Hoffman, M. A. (2003). Development and validation of the Counselor Activity SelfEfficacy Scales. Journal of Counseling Psychology, 50(1), 97-108. https://doi.org/10.1037/0022-0167.50.1.97

Maples, M. F., Packman, J., Abney, P., Daugherty, R. F., Casey, J. A., \& Pirtle, L. (2005). Suicide by teenagers in middle school: A postvention team approach. Journal of Counseling \& Development, 83(4), 397-405. https://doi.org/10.1002/j.1556-6678.2005.tb00361.x

McAdams, C. R., III., \& Foster, V. A. (2002). An assessment of resources for counselor coping and recovery in the aftermath of client suicide. Journal of Humanistic Counseling, Education and Development, 41(2), $232-242$.

McCarthy, J. M., Trougakos, J. P., \& Cheng, B. H. (2016). Are anxious workers less productive workers? It depends on the quality of social exchange. Journal of Applied Psychology, 101(2), 279-291. https://doi.org/10.1037/ap10000044 
Mirick, R. G., Bridger, J., McCauley, J., \& Berkowitz, L. (2016). Continuing education on suicide assessment and crisis intervention for social workers and other mental health professionals: A follow-up study. Journal of Teaching in Social Work, 36(4), 363-379. https://doi.org/10.1080/08841233.2016.1200171

National Institute of Mental Health. (2019). Mental health information: Statistics: Suicide. https://www.nimh.nih. gov/health/statistics/suicide.shtml

Perera-Diltz, D. M., \& Mason, K. L. (2012). A national survey of school counselor supervision practices: Administrative, clinical, peer, and technology mediated supervision. Journal of School Counseling, 10, 1-34. https://files.eric.ed.gov/fulltext/EJ978860.pdf

Substance Abuse and Mental Health Services Administration. (2016). Preventing suicide: A toolkit for high school. Center for Mental Health Services, Substance Abuse and Mental Health Services Administration. https://store.samhsa.gov/product/Preventing-Suicide-A-Toolkit-for-High-Schools/SMA12-4669

Schmidt, R. C. (2016). Mental health practitioners' perceived levels of preparedness, levels of confidence and methods used in the assessment of youth suicide risk. The Professional Counselor, 6(1), 76-88. https://doi.org/10.15241/rs.6.1.76

Sherba, R. T., Linley, J. V., Coxe, K. A., \& Gersper, B. E. (2019). Impact of client suicide on social workers and counselors. Social Work in Mental Health, 17(3), 279-301. https://doi.org/10.1080/15332985.2018.1550028

Solomonson, L. L., \& Killam, W. (2013). A national study on crisis intervention: Are school counselors prepared to respond? Ideas and Research You Can Use: VISTAS 2013. https://www.counseling.org/docs/defaultsource/vistas/a-national-study-on-crisis-intervention.pdf?sfvrsn=b3b9af05 11

Springer, S., Paone, C. H., Colucci, J., \& Moss, L. J. (2020). Addressing suicidality: Examining preservice school counselors' perceptions of their training experiences. Journal of Child and Adolescent Counseling, 6(1), 18-36. https://doi.org/10.1080/23727810.2018.1556990

Stickl Haugen, J., Waalkes, P. L., \& Lambie, G. W. (2021). A national survey of school counselors' experiences with student death by suicide. Professional School Counseling, 25(1), 1-11. https://doi.org/10.1177/2156759X21993804

Tang, A. (2019). The impact of school counseling supervision on practicing school counselors' self-efficacy in building a comprehensive school counseling program. Professional School Counseling, 23(1), 1-11. https://doi.org/10.1177/2156759X20947723

Thomyangkoon, P., \& Leenars, A., (2008). Impact of death by suicide of patients on Thai psychiatrists. Suicide $\mathcal{E}$ Life-Threatening Behavior, 38(6), 728-740. https://doi.org/3994/10.1521/suli.2008.38.6.728

Wachter, C. A. (2006). Crisis in the schools: Crisis, crisis intervention training, and school counselor burnout (Publication No. 3221458). [Doctoral dissertation, University of North Carolina at Greensboro]. ProQuest Dissertations Publishing.

Wachter Morris, C. A., \& Barrio Minton, C. A. (2012). Crisis in the curriculum? New counselors' crisis preparation, experiences, and self-efficacy. Counselor Education and Supervision, 51(4), 256-269. https://doi.org/10.1002/j.1556-6978.2012.00019.x

Wagner, N. J., Grunhaus, C. M. L., \& Tuazon, V. E. (2020). Agency responses to counselor survivors of client suicide. The Professional Counselor, 10(2), 251-265. https://doi.org/10.15241/njw.10.2.251 